\title{
Hyponatremia in the elderly: challenges and solutions
}

\author{
Theodosios D Filippatos \\ Andromachi Makri \\ Moses S Elisaf \\ George Liamis
}

Department of Internal Medicine, School of Medicine, University of loannina, loannina, Greece
Correspondence: George Liamis

Department of Internal Medicine, School of Medicine, University of loannina, 45II 0 loannina, Greece

Tel +302651007516

Email gliamis@cc.uoi.gr
This article was published in the following Dove Press journal:

Clinical Interventions in Aging

14 November 2017

Number of times this article has been viewed

\begin{abstract}
Decreased serum sodium concentration is a rather frequent electrolyte disorder in the elderly population because of the presence of factors contributing to increased antidiuretic hormone, the frequent prescription of drugs associated with hyponatremia and also because of other mechanisms such as the "tea and toast" syndrome. The aim of this review is to present certain challenges in the evaluation and treatment of hyponatremia in the elderly population and provide practical solutions. Hyponatremia in elderly subjects is mainly caused by drugs (more frequently thiazides and antidepressants), the syndrome of inappropriate antidiuretic hormone secretion (SIAD) or endocrinopathies; however, hyponatremia is multifactorial in a significant proportion of patients. Special attention is needed in the elderly population to exclude endocrinopathies as a cause of hyponatremia before establishing the diagnosis of SIAD, which then requires a stepped diagnostic approach to reveal its underlying cause. The treatment of hyponatremia depends on the type of hyponatremia. Special attention is also needed to correct serum sodium levels at the appropriate rate, especially in chronic hyponatremia, in order to avoid the osmotic demyelination syndrome. In conclusion, both the evaluation and the treatment of hyponatremia pose many challenges in the elderly population.
\end{abstract}

Keywords: sodium, prognosis, hypopituitarism, elderly, pituitary

\section{Introduction}

Hyponatremia is the most frequent electrolyte disorder both in hospitalized patients and in community subjects. Elderly patients represent a high-risk group for the occurrence of hyponatremia because age is a strong independent risk factor for hyponatremia. ${ }^{1-4}$ Furthermore, the symptomatology of acute hyponatremia (developed in $<48 \mathrm{~h}$ ) such as nausea, vomiting, headache, stupor, coma and seizures, as well as manifestations (even mild) associated with chronic hyponatremia, such as fatigue, cognitive impairment, gait deficits, falls, adverse effects on bone quality (eg, osteoporosis) and fractures, are more frequent and severe in elderly patients. ${ }^{5-9}$ Relevant studies also indicate that hyponatremia is related with a poor prognosis in elderly subjects, because it is independently associated with an increased mortality risk. ${ }^{1,10}$

Taking into consideration the aging of the population, the increased susceptibility of the elderly to develop electrolyte disorders and the increased morbidity associated with hyponatremia in this population, hyponatremia is of increasing importance. Herein, we present the available data with reference to hyponatremia in the geriatric population focusing mainly on practical issues regarding its diagnosis and treatment.

\section{Prevalence of hyponatremia in the elderly}

The prevalence of hyponatremia in the elderly, similar to the general population, varies considerably depending on the population at risk and the sodium concentration used 
to define the condition. The most frequently used "normal range" of serum sodium levels is $135-142 \mathrm{mmol} / \mathrm{L}$, but other stricter definitions of hyponatremia have been proposed based on a $U$-shaped association of serum sodium concentration with mortality. ${ }^{11-14}$ The prevalence of hyponatremia in the community is $\sim 8 \%$ and it is increased significantly with age. ${ }^{1,2}$ In this context, $7.7 \%$ of participants aged 55 years or more exhibited hyponatremia (serum sodium concentration $<136 \mathrm{mmol} / \mathrm{L}$ ) in the population-based Rotterdam Study, whereas the prevalence of hyponatremia was higher in subjects $\geq 75$ years of age $(11.6 \%)$. The prevalence of low serum sodium levels is even higher in the health care setting. For example, Miller et al found that $18 \%$ of a nursing home population aged $>60$ years had hyponatremia (serum sodium concentration $<135 \mathrm{mmol} / \mathrm{L}$ ). ${ }^{15}$ Moreover, when multiple serum sodium measurements were conducted during a 12-month period, at least one episode of hyponatremia was observed in approximately half of the patients. Similarly, another prospective study in hospitalized patients $>65$ years showed that one-third of participants had serum sodium $<135 \mathrm{mmol} / \mathrm{L}^{16}$

\section{Pathogenetic mechanisms of increased susceptibility of the elderly to develop hyponatremia}

The greater propensity of the elderly to develop hyponatremia is mainly ascribed to 1) the aging-related impaired water-excretory capacity, and 2) the frequent exposure to medications and diseases associated with hyponatremia., ${ }^{3,17}$ In elderly patients, multiple factors are usually implicated in the development of hyponatremia.

Older subjects are more prone to hyponatremia because of impaired water-excretory capacity mainly attributed to aging-related reduction of glomerular filtration rate (GFR). Additionally, the decreased intrarenal generation of prostaglandins seen in advanced age may also be involved in the impaired ability of elderly individuals to excrete water. ${ }^{18}$ Another contributing factor in elderly patients is the age-related reduction in the percentage of total body water content, leading to greater fluctuations in serum sodium concentration, because: serum sodium levels = exchangeable total (sodium + potassium)/total body water.

Furthermore, a higher sensitivity to osmotic stimuli may be evident in geriatric population given that the relatively rare idiopathic syndrome of inappropriate antidiuretic hormone secretion (SIAD) is more frequently observed in elderly subjects. ${ }^{19,20}$

Despite the above pathogenetic factors, the urinary diluting ability is preserved in most elderly persons, even with a low GFR, and hyponatremia develops only in the presence of increased water intake and additional precipitating or/and superimposed factors. In this context, elderly individuals frequently take drugs (eg, thiazide diuretics, selective serotonin reuptake inhibitors [SSRIs], serotonin-norepinephrine reuptake inhibitors [SNRIs], nonsteroidal anti-inflammatory drugs [NSAIDs]) or/and suffer from diseases (eg, diabetes mellitus [DM], infections, heart failure, liver diseases, malignancies, endocrinopathies) that are all well-established causes of hyponatremia. ${ }^{21-26}$ Moreover, many elderly patients with hypertension or heart failure follow a low-salt diet that is associated with decreased serum sodium concentration. Additionally, in this population, the frequent reduction in protein intake (habitual or due to superimposed illness) that impairs water excretion may also play a role in the development of hyponatremia. ${ }^{27,28}$ It should also be mentioned that hyponatremia follows a seasonal variation (higher incidence during the summer) because of more frequent impairment of renal function, increased salt losses, diminished salt intake and increased water ingestion. ${ }^{29}$

\section{Causes of hyponatremia of special interest in the elderly Drugs}

Diuretics make up one of the most common causes of hyponatremia in the elderly. ${ }^{28}$ Thiazide diuretics are usually associated with hyponatremia, while loop diuretics only occasionally induce hyponatremia. ${ }^{1,3,30-39}$ The incidence of thiazide-induced hyponatremia has not been clearly determined, because additional risk factors for low serum sodium levels are usually present. A study reported that $\sim 14 \%$ of thiazide-treated outpatients had hyponatremia (serum sodium concentration $<135 \mathrm{mmol} / \mathrm{L}$ ), whereas age $>70$ years was associated with a fourfold increase in the risk of hyponatremia. ${ }^{40}$ Thiazide-associated hyponatremia is more frequent in patients with heart failure, liver disease or malignancy, and in those taking large doses of thiazides or several medications, such as NSAIDs, SSRIs or tricyclic antidepressants. ${ }^{28}$ Clues for the diagnosis of thiazide diuretics-associated hyponatremia are given below in the "Challenges" section.

A wide array of psychotropic medications, including antipsychotic drugs (phenothiazines, butyrophenones), benzodiazepines and more frequently antidepressants, is associated with hyponatremia. It has recently been reported that SSRIs, SNRIs and mirtazapine account for the majority of hyponatremia cases related to antidepressants in adults 60 years of age or older, while bupropion, trazodone and tricyclic antidepressants are implicated less often. ${ }^{41}$ 
Main implicating mechanism is the development of SIAD (see below for details). ${ }^{1,21}$ Female gender, low body mass index, low baseline serum sodium, concomitant nonpsychiatric medication use, such as diuretics, NSAIDs, protonpump inhibitors, angiotensin-converting enzyme inhibitors, as well as the presence of heart failure, malignancy, liver disease or adrenal insufficiency are important factors that contribute to the development of psychotropic medicationsassociated hyponatremia in the elderly. ${ }^{21,42}$

Carbamazepine and oxcarbazepine are the most common antiepileptic drugs (AEDs) associated with hyponatremia. ${ }^{1,21}$ Recently, other AEDs, such as eslicarbazepine, sodium valproate, lamotrigine, levetiracetam and gabapentin, have also been reported to induce hyponatremia. ${ }^{43}$ In fact, older adults on valproic acid, phenytoin or topiramate have a higher risk of being hospitalized with hyponatremia compared with those who do not receive AEDs. ${ }^{44}$

\section{SIAD}

SIAD is one of the more frequent causes of hyponatremia especially in the elderly. Although direct comparisons of the prevalence of SIAD between elderly and younger matched controls are missing, it has been found that aging is accompanied by an increase in plasma vasopressin concentrations. ${ }^{45}$ In a prospective study that included patients $>65$ years, SIAD was the main factor in half of the patients with hyponatremia (serum sodium $<135 \mathrm{mmol} / \mathrm{L}$ ). ${ }^{46}$ SIAD was also the leading cause of hyponatremia in elderly hospitalized patients with severe hyponatremia (serum sodium $\leq 125 \mathrm{mmol} / \mathrm{L}$ ). ${ }^{19}$ Of note, even the relatively rare idiopathic SIAD is more common among the elderly. Indeed, in two relevant studies the underlying etiology of SIAD was not identified in 54\% and $60 \%$ of cases, respectively. ${ }^{19,47}$ Clues for the diagnosis of SIAD are given below in the "Challenges" section.

\section{Endocrinopathies}

Hypopituitarism should not be considered as a rare cause of hyponatremia especially in patients aged 65 years or older. ${ }^{48,49}$ Indeed, Ishikawa et al reported that $40 \%$ of patients aged 65 years or older presenting with hyponatremia have pituitary adrenal dysfunction. ${ }^{48}$ Thus, secondary adrenal insufficiency is frequently an overlooked cause of hyponatremia. ${ }^{22}$ Hypopituitarism is more difficult to be diagnosed in the elderly patients in whom symptoms such as weakness or easy fatigability may be ascribed either to aging per se or to associated comorbidities. ${ }^{50}$

The prevalence of DM is high among the elderly population. In cases of marked hyperglycemia, serum osmolality (Posm) is increased, because glucose is an osmotic active substance, leading to movement of water out of cells and subsequently to a reduction of serum sodium levels by dilution. Uncontrolled DM can also induce osmotic diuresis and hypovolemic hyponatremia. In this setting of uncontrolled DM, hypovolemia is an almost invariable finding because of osmotic diuresis and hypotonic fluid losses (losses of water in excess of electrolytes), which when accompanied with large intake of water (without solutes) or administration of more hypotonic solutions may lead to hyponatremia. ${ }^{51,52}$ Noteworthy, DM per se is associated with hyponatremia, independent of the presence of hyperglycemia. ${ }^{1,25,53}$

\section{"Tea and toast" hyponatremia}

This type of hyponatremia may occur in elderly individuals with a low GFR who follow a diet poor in salt and protein but drink a large amount of water. In these cases, there is a low distal delivery of filtrate (due to low GFR and possibly chronic sodium deficit) and increased water reabsorption due to the low rate of osmoles excretion; thus, when water consumption exceeds the renal water excretion capacity, hyponatremia occurs. ${ }^{54}$

\section{Challenges in diagnosing hyponatremia in the elderly Possible pseudohyponatremia or hyperglycemia-induced hyponatremia}

Pseudohyponatremia is observed in patients with hyperproteinemia (as seen in multiple myeloma and other monoclonal gammopathies or with intravenous immunoglobulin administration) and severe hyperlipidemia (hypertriglyceridemia and hypercholesterolemia). ${ }^{55}$ The opposite phenomenon of spurious higher serum sodium levels (pseudohypernatremia, pseudonormonatremia in cases of true normo/or hyponatremia, respectively) may also occur when sodium is measured with methods requiring a predilution step, as a result of severe hypoproteinemia that is not infrequently observed in the elderly. ${ }^{56}$ In clinical settings predisposing to unreliable serum sodium concentrations (severe hyperproteinemia, hypoalbuminemia, hypertriglyceridemia or hypercholesterolemia), measurement of the effective serum osmolality (tonicity), that is: effective serum osmolality = measured serum osmolality - serum urea $(\mathrm{mmol} / \mathrm{L})$ differentiates between true hyponatremia (hypotonicity), pseudohyponatremia (normal tonicity) and hyponatremia due to increased concentrations of osmotically active substances, such as glucose and mannitol (increased tonicity).${ }^{57}$ Alternatively, measurement of serum sodium levels with a direct potentiometer (using one of the most modern blood gas analyzers) can reliably detect the true serum sodium concentration. ${ }^{58}$ 
In patients with hyperglycemia, sodium concentration should be corrected for the degree of hyperglycemia. Corrected serum sodium is calculated by adding to measured serum sodium $1.6 \mathrm{mmol} / \mathrm{L}$ for every $100 \mathrm{mg} / \mathrm{dL}$ $(5.55 \mathrm{mmol} / \mathrm{L})$ increment of serum glucose above normal up to $400 \mathrm{mg} / \mathrm{dL}$ and by adding to measured serum sodium $2.4 \mathrm{mmol} / \mathrm{L}$ when serum glucose concentrations are higher than $400 \mathrm{mg} / \mathrm{dL}(22.2 \mathrm{mmol} / \mathrm{L})$.

\section{Evaluation of the cause of hypotonic hyponatremia}

Clinicians should follow a diagnostic algorithm in patients with hyponatremia in order to avoid certain pitfalls. ${ }^{59}$ Hyponatremia evaluation requires a diagnostic workup of hypopituitarism (secondary adrenal insufficiency) especially in the elderly. ${ }^{60}$ Hypopituitarism and, to a lesser degree, primary adrenal insufficiency (ie, Addison's disease) are causes of hyponatremia that are not straightforwardly discriminated from SIAD by routine laboratory studies and volume status assessment; thus, the measurement of associated laboratory parameters is mandatory for the diagnosis of hypothalamic-pituitary-adrenal axis disorders. ${ }^{22}$

Hypothyroidism is more frequently observed among elderly persons because of the increasing incidence and prevalence of autoimmune thyroiditis. ${ }^{61}$ Hypothyroidism is among the causes of hyponatremia, and the exclusion of this endocrine disease is a prerequisite for the diagnosis of SIAD. However, hypothyroidism-induced hyponatremia is rather rare and probably occurs only in severe hypothyroidism. ${ }^{62}$ Thus, in a euvolemic hypothyroid elderly patient with thyroid-stimulating hormone $<50 \mathrm{mIU} / \mathrm{mL}$, after a comprehensive diagnostic workup (including primary and secondary adrenal insufficiency), idiopathic SIAD is the most possible diagnosis if normonatremia has not been achieved with thyroid hormone replacement. It should be emphasized than even in myxedema coma, other probable causes and superimposed factors of hyponatremia (eg, drugs, infections, adrenal insufficiency) should be thoroughly investigated. ${ }^{62}$

Urine osmolality (Uosm) is a useful tool in the evaluation of the hyponatremic patient because it can establish the diagnosis of psychogenic polydipsia. ${ }^{57}$ Accordingly, Uosm $<100 \mathrm{mosmol} / \mathrm{kg}$ (or a specific gravity $\leq 1.003$ ) is usually found in patients with psychogenic polydipsia. However, hyponatremia with reduced Uosm has been also reported in ill-nourished heavy drinkers (beer potomania syndrome), in reset osmostat syndrome (eg, in patients with quadriplegia, malignant disorders or chronic malnutrition) but also in elderly patients with increased water and low solute intake (for example, tea and toast diet).

The assessment of the extracellular volume status is of vital importance in the evaluation of hyponatremia, because it helps to differentiate between hypovolemic, euvolemic and hypervolemic hyponatremia. A drop in systolic pressure of greater than $10-20 \mathrm{mmHg}$ or an increase in heart rate greater than 15 beats/minute after 3 minutes of standing suggests orthostatic hypotension (a major sign of hypovolemia especially in case of a greater than 30 beats/minute increase in heart rate). ${ }^{63}$ However, postural changes in blood pressure and nonhypovolemic orthostatic hypotension are frequently encountered in non-volume-depleted elderly subjects due mainly to autonomic dysfunction (a failure of the heart rate to increase may indicate autonomic dysfunction), medications or other systemic diseases; thus, it is often difficult to differentiate between hypovolemic and euvolemic hyponatremia based solely on clinical grounds in elderly patients. ${ }^{64}$

Urine sodium concentration should be measured in patients with hyponatremia, because in patients with according clinical findings a level $<30 \mathrm{mmol} / \mathrm{L}$ strongly indicates hypovolemia. ${ }^{65}$ However, a low urine sodium concentration may not be observed in elderly people who may have slower adaptive mechanisms to retain sodium in the context of hypovolemia.

Certain laboratory clues that suggest SIAD are urine sodium levels $>30 \mathrm{mmol} / \mathrm{L}$, hypouricemia $(<4 \mathrm{mg} / \mathrm{dL})$ and urea levels $<20 \mathrm{mg} / \mathrm{dL} .{ }^{59}$ However, these biochemical parameters should be interpreted critically especially in the elderly. As aforementioned, elderly people are usually on a low-salt diet or suffer from anorexia. Under these circumstances, urine sodium levels $<30 \mathrm{mmol} / \mathrm{L}$ can be found in patients with chronic SIAD. Moreover, there is an increase in plasma urea level attributed to an age-related reduction in fractional urea excretion. ${ }^{66}$ Additionally, hypouricemia accompanied by a high fractional excretion (FE) of uric acid ( $>12 \%$ in the general population; $>16 \%$ in the elderly) is observed not only in SIAD but also in other conditions, such as hypocortisolism, diuretics, potomania and renal salt wasting..$^{59,67-69}$

Therefore, the differentiation between hypovolemic hyponatremia and SIAD is often difficult in elderly subjects. In such cases, the administration of normal saline (1-2 L/day for 2 days) provides important clues, because an increase of $>5 \mathrm{mmol} / \mathrm{L}$ in serum sodium level combined with an increase of $<0.5 \%$ in $\mathrm{FE}$ of sodium $\left(\mathrm{FENa}^{+}\right)$is highly suggestive of hypovolemic hyponatremia. In contrast, an increase of $>0.5 \%$ in $\mathrm{FENa}^{+}$and an increase of $<5 \mathrm{mmol} / \mathrm{L}$ 
is indicative of SIAD. ${ }^{65}$ In the last case, even a fall in serum sodium levels could be observed because of the fact that the administered sodium is excreted in a small volume of concentrated urine and some water is retained.

As described above, drugs are among the most common causes of hyponatremia. Although there is a wide variation in the timing of presentation of drug-induced hyponatremia, it occurs within the first few weeks of the onset of therapy in the majority of cases. ${ }^{21,42}$ Thus, the emergence of low serum sodium levels in a patient after receiving a drug for a prolonged period of time should raise the suspicion for the presence of an additional predisposing or/and superimposed factor of hyponatremia (eg, infection). ${ }^{70}$

Thiazide diuretics are among the most common causes of drug-induced hyponatremia. An increased potassium excretion ( $\mathrm{FE}$ of $\mathrm{K}^{+}>13 \%$ ) is a useful marker for the diagnosis of thiazide-induced hyponatremia. ${ }^{71}$ Clinicians should be aware that there are two groups of patients with thiazideinduced hyponatremia, one with a biochemical profile that is consistent with extracellular volume depletion and another that simulates the SIAD. Regarding the latter group, recent investigations have identified a phenotype resembling SIAD, with intravascular volume expansion, low plasma osmolarity, inappropriately concentrated urine and more than minimal urinary sodium excretion but with low/normal ADH levels. ${ }^{72}$ In this phenotype, the SLCO2A1 A396T gene variant (that encodes the solute carrier organic anion transporter family member 2A1 [SLCO2A1], also known as the prostaglandin transporter), which is associated with increased urinary excretion of prostaglandin E2 and aquaporin-2-mediated water reabsorption, has been identified to contribute to thiazide-induced hyponatremia. ${ }^{72}$ Serum uric acid level can differentiate between the extracellular volume depletionassociated and the SIAD-like thiazide-induced hyponatremia. Specifically, serum uric acid concentration $<4 \mathrm{mg} / \mathrm{dL}$ points to an SIAD-like state, whereas serum uric acid concentration $>4 \mathrm{mg} / \mathrm{dL}$ points to extracellular volume depletion. ${ }^{69}$ In patients with diuretic-related hyponatremia and an SIADlike profile, unless there is strong evidence to suggest an underlying cause for SIAD, a thorough diagnostic evaluation of SIAD (see below) should be delayed for 2-3 weeks to see if serum sodium levels are fully corrected with diuretic discontinuation. However, taking into account that thiazides may worsen the hyponatremia induced by SIAD, this evaluation should be undertaken if even mild hyponatremia persists after this diagnostic waiting period. ${ }^{59}$

Finally, one of the most challenging issues in the evaluation of elderly persons with SIAD is to reveal the underlying cause given that this syndrome can be seen in a wide variety of clinical states (eg, numerous drugs, malignancies, pulmonary and neuropsychiatric diseases) and simultaneously in a considerable fraction of patients is idiopathic. It should be emphasized that a clinically driven-through approach for the identification of the underlying cause of SIAD before the diagnosis of idiopathic SIAD is of paramount importance. A detailed medical history with emphasis in drugs and diseases affecting water homeostasis including infections and malignancies, a complete physical examination and appropriate investigations depending on the cause identified by the clinical features are necessary. Furthermore, rare causes of the syndrome such as temporal arteritis or Waldenstrom macroglobulinemia can be considered in suspected cases. In case of SIAD with no evident cause, careful and repeated monitoring for the presence of an occult tumor (particularly pulmonary) is of vital importance..$^{59}$

\section{Solutions}

\section{Prevention strategies of hyponatremia in the elderly}

Clinicians should prescribe drugs with caution in elderly patients, especially in those with risk factors to develop SIAD. The avoidance of polypharmacy, especially with drugs implicated in the development of hyponatremia, should be a priority in elderly people. Additionally, the use of low doses of suspected drugs or alternative therapies may be preferable in many cases. ${ }^{21,26,28,73,74}$ For example, low doses of thiazide diuretics (equivalent to $12.5 \mathrm{mg}$ of hydrochlorothiazide) should be prescribed in high-risk patients for hyponatremia or alternative antihypertensive treatment not associated with hyponatremia (eg, a calciumchannel blocker or beta-blockers) should be selected. In fact, a population-based study ( $\mathrm{n}=13,325$ individuals, age $>45$ years old), thiazide diuretic exposure was associated with an almost 5 times higher risk of hyponatremia than nonexposure (hazard ratio [HR] 4.95, 95\% CI 4.12-5.96). Moreover, exposure with an equal or greater than 1 standardized defined daily thiazide dose was associated with a significantly higher risk of hyponatremia than exposure below 1 standardized defined daily thiazide dose (HR 5.72 [95\% CI 4.67-7.00] and 3.42 [95\% CI 2.46-4.77], respectively). ${ }^{75}$ In another study in hypertensive patients with hyponatremia (average daily dose of the hydrochlorothiazide $35 \pm 18 \mathrm{mg}$ ), $44 \%$ of the patients used a dose greater than $50 \mathrm{mg}$ daily, whereas only $10 \%$ of the patients received a low thiazide dose ( $12.5 \mathrm{mg}$ daily) ${ }^{76}$ Especially in patients with thiazide-induced hyponatremia, furosemide 
or torsemide may be alternatively prescribed without risk of recurrent hyponatremia. ${ }^{28}$

In patients at risk for or with a history of antidepressantinduced hyponatremia, bupropion may be the most appropriate antidepressant treatment. ${ }^{41}$ Mirtazapine could be also used alternatively because the associated risk of hyponatremia is moderate. ${ }^{77}$

Generally, discontinuation of treatment with agents implicated in the development of hyponatremia and avoidance of readministration is fully warranted. However, given that chronic hyponatremia is frequently multifactorial in the elderly, ${ }^{19}$ there is increased risk of unnecessary discontinuation of treatments, especially if patients have responded favorably to therapy (eg, a patient on antidepressants with well-controlled symptoms). In such cases, the discontinuation of the most recent suspected medication(s) is a useful strategy.

The administration of hypotonic fluids as maintenance therapy, for the avoidance of volume overload, is common clinical practice in hospitalized elderly patients. However, this procedure, especially in cases accompanied by elevated antidiuretic hormone (ADH) levels (eg, central nervous system disturbances, pulmonary disease, cancer), may lead to hyponatremia and should be avoided. It has been proposed that isotonic fluids are the most suitable maintenance fluid in most circumstances including compensated heart failure. ${ }^{78}$ For example, in an elderly hospitalized individual with well-controlled congestive heart failure, 5\% dextrose in a solution of $0.9 \%$ saline at a rate of $60 \mathrm{~mL}$ per hour could be an appropriate maintenance fluid therapy. ${ }^{65,79}$

\section{Treatment of hyponatremia in the elderly}

Although there is no concrete evidence that the restoration of hyponatremia is associated with improved outcome, it is prudent to correct low sodium concentration even in "asymptomatic elderly individuals" because it is related to increased mortality and morbidity (eg, gait disturbances, falls, cognition impairment). The indication for treatment is stronger in subjects having disorders that could be attributed to the decreased sodium concentration.

In acute symptomatic hyponatremia, hypertonic saline solution (3\%) is commonly used to acutely increase serum sodium levels and prevent severe neurologic symptoms (eg, seizures). Hypovolemic hyponatremia is treated with adequate fluid resuscitation to decrease the stimulus for ADH secretion. Normal saline is usually used to suppress the hypovolemic stimulus for ADH release. ${ }^{65,80}$ In patients with SIAD, along with discontinuation of suspected drugs and decrease of water consumption, careful administration of hypertonic fluids may be needed. In these cases, furosemide (20-40 mg intravenously) can also be administered to avoid circulatory overload, particularly if there is concomitant cardiac dysfunction in elderly persons. Furosemide increases free water excretion and contributes to serum sodium elevation. Vaptans (vasopressin-2 antagonists) are a class of drugs that selectively antagonize the antidiuretic effect of vasopressin leading to increased water diuresis (aquaresis). ${ }^{81,82}$ These drugs can be used in hospitalized patients with chronic symptomatic euvolemic hyponatremia (mainly in patients with SIAD) and in some countries in patients with hypervolemic hyponatremia. ${ }^{82-88}$ A retrospective study $(n=37$, aged median 77 years) reported that lower starting doses of tolvaptan $(7.5 \mathrm{mg} /$ day) are effective and possibly safer to correct hyponatremia in elderly individuals with SIAD. ${ }^{89}$ However, the use of these drugs in elderly population needs more investigation.

The proper correction rate of serum sodium levels in patients with hyponatremia is of great importance. Overcorrection of serum sodium concentration may lead to the osmotic demyelination syndrome (ODS), especially in alcoholic individuals and patients with hypokalemia, malnutrition or advanced liver disease. ${ }^{90-95}$ In cases of acute symptomatic hyponatremia, an acute elevation of serum sodium concentration by $4-6 \mathrm{mEq} / \mathrm{L}$ within the first $4-6 \mathrm{~h}$ is recommended in order to reverse the symptoms. ${ }^{12}$ In chronic hyponatremia, even symptomatic, the rate of the correction of serum sodium concentration should be restricted at $<10 \mathrm{mEq} / \mathrm{L} / 24 \mathrm{~h}$ and more safely at $<6-8 \mathrm{mEq} / \mathrm{L} / 24$ h. ${ }^{96,97}$ Frequent determination of serum sodium concentration (every 4-6 h) and appropriate tailoring of the correction rate is strongly recommended in patients with high risk of developing the ODS. ${ }^{98}$ A number of formulas can be used to predict the change of serum sodium levels during treatment and to calculate the initial infusion rates. ${ }^{98}$ Special attention is needed in patients with hypovolemic hyponatremia for a rapid increase in serum sodium levels when volume depletion is restored because of the abrupt decrease in ADH secretion. ${ }^{65,98}$

It has been mentioned above that it is difficult to distinguish between hyponatremia due to disorders of pituitaryadrenal axis and SIAD in elderly individuals. It has been proposed that in cases of hyponatremic elderly individuals with such diagnostic uncertainty, the administration of lowdose hydrocortisone (10 mg/day or less) may be of value. Indeed, Takei et al reported five cases of severe hyponatremia in the elderly successfully treated with low doses of hydrocortisone suggesting adrenal insufficiency as the 
underlying cause for the low serum sodium concentration. ${ }^{99}$ However, replacement with hydrocortisone may require many days to restore serum sodium levels (in the cases by Takei et al up to 179 days was needed) $;{ }^{99}$ thus, it can be used as a diagnostic tool only in cases of relatively rapid treatment of hyponatremia.

\section{Conclusion}

Decreased serum sodium concentration is a rather common finding in the elderly population because of the presence of factors contributing to increased $\mathrm{ADH}$ and the frequent prescription of drugs associated with hyponatremia such as thiazides or antidepressants. Both the evaluation and the treatment of hyponatremia pose many challenges in the elderly population.

\section{Disclosure}

This review was conducted independently. Professor Elisaf reports personal fees from Astra-Zeneca, grants and personal fees from MSD, personal fees from Pfizer, Abbott, SanofiAventis, Boehringer Ingelheim, Eli-Lilly and GSK. The authors have given talks and attended conferences sponsored by various pharmaceutical companies, including BristolMyers Squibb, Pfizer, Lilly, Abbott, Amgen, AstraZeneca, Novartis, Vianex, Teva and MSD. The authors report no other conflicts of interest in this work.

\section{References}

1. Liamis G, Rodenburg EM, Hofman A, Zietse R, Stricker BH, Hoorn EJ Electrolyte disorders in community subjects: prevalence and risk factors. Am J Med. 2013;126(3):256-263.

2. Hawkins RC. Age and gender as risk factors for hyponatremia and hypernatremia. Clin Chim Acta. 2003;337(1-2):169-172.

3. Upadhyay A, Jaber BL, Madias NE. Epidemiology of hyponatremia. Semin Nephrol. 2009;29(3):227-238.

4. Lindner G, Pfortmuller CA, Leichtle AB, Fiedler GM, Exadaktylos AK. Age-related variety in electrolyte levels and prevalence of dysnatremias and dyskalemias in patients presenting to the emergency department Gerontology. 2014;60(5):420-423.

5. Renneboog B, Musch W, Vandemergel X, Manto MU, Decaux G. Mild chronic hyponatremia is associated with falls, unsteadiness, and attention deficits. Am J Med. 2006;119(1):71.e1-8.

6. Hoorn EJ, Rivadeneira F, van Meurs JB, et al. Mild hyponatremia as a risk factor for fractures: the Rotterdam Study. J Bone Miner Res. 2011; 26(8):1822-1828.

7. Renneboog B, Sattar L, Decaux G. Attention and postural balance are much more affected in older than in younger adults with mild or moderate chronic hyponatremia. Eur J Intern Med. 2017;41:e25-e26.

8. Gosch M, Joosten-Gstrein B, Heppner HJ, Lechleitner M. Hyponatremia in geriatric inhospital patients: effects on results of a comprehensive geriatric assessment. Gerontology. 2012;58(5):430-440.

9. Hoorn EJ, Liamis G, Zietse R, Zillikens MC. Hyponatremia and bone: an emerging relationship. Nat Rev Endocrinol. 2011;8(1):33-39.

10. Sajadieh A, Binici Z, Mouridsen MR, Nielsen OW, Hansen JF, Haugaard SB. Mild hyponatremia carries a poor prognosis in community subjects. Am J Med. 2009;122(7):679-686.
11. Sterns RH. Disorders of plasma sodium-causes, consequences, and correction. N Engl J Med. 2015;372(1):55-65.

12. Verbalis JG, Goldsmith SR, Greenberg A, et al. Diagnosis, evaluation, and treatment of hyponatremia: expert panel recommendations. $\mathrm{Am} \mathrm{J}$ Med. 2013;126(10 Suppl 1):S1-S42.

13. Wald R, Jaber BL, Price LL, Upadhyay A, Madias NE. Impact of hospital-associated hyponatremia on selected outcomes. Arch Intern Med. 2010;170(3):294-302.

14. Mohan S, Gu S, Parikh A, Radhakrishnan J. Prevalence of hyponatremia and association with mortality: results from NHANES. Am J Med. 2013;126(12):1127-1137.e1.

15. Miller M, Morley JE, Rubenstein LZ. Hyponatremia in a nursing home population. J Am Geriatr Soc. 1995;43(12):1410-1413.

16. Frenkel WN, van den Born BJ, van Munster BC, Korevaar JC, Levi M, de Rooij SE. The association between serum sodium levels at time of admission and mortality and morbidity in acutely admitted elderly patients: a prospective cohort study. J Am Geriatr Soc. 2010;58(11):2227-2228.

17. Mannesse CK, Vondeling AM, van Marum RJ, van Solinge WW, Egberts TC, Jansen PA. Prevalence of hyponatremia on geriatric wards compared to other settings over four decades: a systematic review. Ageing Res Rev. 2013;12(1):165-173.

18. Clark BA, Shannon RP, Rosa RM, Epstein FH. Increased susceptibility to thiazide-induced hyponatremia in the elderly. J Am Soc Nephrol. 1994;5(4):1106-1111.

19. Shapiro DS, Sonnenblick M, Galperin I, Melkonyan L, Munter G. Severe hyponatraemia in elderly hospitalized patients: prevalence, aetiology and outcome. Intern Med J. 2010;40(8):574-580.

20. Helderman JH, Vestal RE, Rowe JW, Tobin JD, Andres R, Robertson GL. The response of arginine vasopressin to intravenous ethanol and hypertonic saline in man: the impact of aging. J Gerontol. 1978;33(1): 39-47.

21. Liamis G, Milionis H, Elisaf M. A review of drug-induced hyponatremia. Am J Kidney Dis. 2008;52(1):144-153.

22. Liamis G, Milionis HJ, Elisaf M. Endocrine disorders: causes of hyponatremia not to neglect. Ann Med. 2011;43(3):179-187.

23. Liamis G, Milionis HJ, Elisaf M. Hyponatremia in patients with infectious diseases. J Infect. 2011;63(5):327-335.

24. Liamis G, Filippatos TD, Liontos A, Elisaf MS. Hyponatremia in patients with liver diseases: not just a cirrhosis-induced hemodynamic compromise. Hepatol Int. 2016;10(5):762-772.

25. Liamis G, Liberopoulos E, Barkas F, Elisaf M. Diabetes mellitus and electrolyte disorders. World J Clin Cases. 2014;2(10):488-496.

26. Liamis G, Filippatos TD, Elisaf MS. Electrolyte disorders associated with the use of anticancer drugs. Eur J Pharmacol. 2016;777:78-87.

27. Frenkel NJ, Vogt L, De Rooij SE, et al. Thiazide-induced hyponatraemia is associated with increased water intake and impaired ureamediated water excretion at low plasma antidiuretic hormone and urine aquaporin-2. J Hypertens. 2015;33(3):627-633.

28. Liamis G, Filippatos TD, Elisaf MS. Thiazide-associated hyponatremia in the elderly: what the clinician needs to know. J Geriatr Cardiol. 2016; 13(2):175-182.

29. Giordano M, Ciarambino T, Castellino P, et al. Seasonal variations of hyponatremia in the emergency department: age-related changes. Am J Emerg Med. 2017;35(5):749-752.

30. Sonnenblick M, Friedlander Y, Rosin AJ. Diuretic-induced severe hyponatremia. Review and analysis of 129 reported patients. Chest. 1993; 103(2):601-606.

31. Friedman E, Shadel M, Halkin H, Farfel Z. Thiazide-induced hyponatremia. Reproducibility by single dose rechallenge and an analysis of pathogenesis. Ann Intern Med. 1989;110(1):24-30.

32. Ashraf N, Locksley R, Arieff AI. Thiazide-induced hyponatremia associated with death or neurologic damage in outpatients. Am J Med. 1981;70(6):1163-1168.

33. Fichman MP, Vorherr H, Kleeman CR, Telfer N. Diuretic-induced hyponatremia. Ann Intern Med. 1971;75(6):853-863.

34. Chow KM, Szeto CC, Wong TY, Leung CB, Li PK. Risk factors for thiazide-induced hyponatraemia. QJM. 2003;96(12):911-917. 
35. Chow KM, Kwan BC, Szeto CC. Clinical studies of thiazide-induced hyponatremia. J Natl Med Assoc. 2004;96(10):1305-1308.

36. Sardar GK, Eilbert WP. Severe hyponatremia associated with thiazide diuretic use. J Emerg Med. 2015;48(3):305-309.

37. Cohen DL, Townsend RR. Hyponatremia and thiazides. J Clin Hypertens (Greenwich). 2012;14(9):653.

38. Ellison DH, Loffing J. Thiazide effects and adverse effects: insights from molecular genetics. Hypertension. 2009;54(2):196-202.

39. Upadhyay A, Jaber BL, Madias NE. Incidence and prevalence of hyponatremia. Am J Med. 2006;119(7 Suppl 1):S30-S35.

40. Clayton JA, Rodgers S, Blakey J, Avery A, Hall IP. Thiazide diuretic prescription and electrolyte abnormalities in primary care. Br J Clin Pharmacol. 2006;61(1):87-95.

41. Viramontes TS, Truong H, Linnebur SA. Antidepressant-induced hyponatremia in older adults. Consult Pharm. 2016;31(3):139-150.

42. Greenblatt HK, Greenblatt DJ. Antidepressant-associated hyponatremia in the elderly. J Clin Psychopharmacol. 2016;36(6):545-549.

43. Lu X, Wang X. Hyponatremia induced by antiepileptic drugs in patients with epilepsy. Expert Opin Drug Saf. 2017;16(1):77-87.

44. Gandhi S, McArthur E, Mamdani MM, et al. Antiepileptic drugs and hyponatremia in older adults: two population-based cohort studies. Epilepsia. 2016;57(12):2067-2079.

45. Johnson AG, Crawford GA, Kelly D, Nguyen TV, Gyory AZ. Arginine vasopressin and osmolality in the elderly. J Am Geriatr Soc. 1994;42(4): 399-404.

46. Anpalahan M. Chronic idiopathic hyponatremia in older people due to syndrome of inappropriate antidiuretic hormone secretion (SIADH) possibly related to aging. J Am Geriatr Soc. 2001;49(6):788-792.

47. Hirshberg B, Ben-Yehuda A. The syndrome of inappropriate antidiuretic hormone secretion in the elderly. Am J Med. 1997;103(4):270-273.

48. Ishikawa S, Saito T, Fukagawa A, et al. Close association of urinary excretion of aquaporin-2 with appropriate and inappropriate arginine vasopressin-dependent antidiuresis in hyponatremia in elderly subjects. J Clin Endocrinol Metab. 2001;86(4):1665-1671.

49. Foppiani L, Ruelle A, Bandelloni R, Quilici P, Del Monte P. Hypopituitarism in the elderly: multifaceted clinical and biochemical presentation. Curr Aging Sci. 2008;1(1):42-50.

50. Diederich S, Franzen NF, Bahr V, Oelkers W. Severe hyponatremia due to hypopituitarism with adrenal insufficiency: report on 28 cases. Eur J Endocrinol. 2003;148(6):609-617.

51. Chonchol M, Berl T. Hyponatremia. In: DuBose TD, Hamm LL, editors. Acid-Base and Electrolyte Disorders: A Companion to Brenner \& Rector's The Kidney. Philadelphia, PA: Saunders; 2002:231-232.

52. Adrogue HJ, Madias NE. Hyponatremia. N Engl J Med. 2000;342(21): 1581-1589.

53. Beukhof CM, Hoorn EJ, Lindemans J, Zietse R. Novel risk factors for hospital-acquired hyponatraemia: a matched case-control study. Clin Endocrinol (Oxf). 2007;66(3):367-372.

54. Thaler SM, Teitelbaum I, Berl T. "Beer potomania" in non-beer drinkers: effect of low dietary solute intake. Am J Kidney Dis. 1998;31(6): 1028-1031.

55. Liamis G, Liberopoulos E, Barkas F, Elisaf M. Spurious electrolyte disorders: a diagnostic challenge for clinicians. Am J Nephrol. 2013; 38(1):50-57.

56. Dimeski G, Morgan TJ, Presneill JJ, Venkatesh B. Disagreement between ion selective electrode direct and indirect sodium measurements: estimation of the problem in a tertiary referral hospital. J Crit Care. 2012;27(3):326.e9-16.

57. Assessment of hyponatraemia. BMJ Best practice. Available from: http://bestpractice.bmj.com/best-practice/monograph/57/diagnosis/ step-by-step.html. Accessed at Aug 5, 2017.

58. Liamis G, Filippatos TD, Liontos A, Elisaf MS. Serum osmolal gap in clinical practice: usefulness and limitations. Postgrad Med. 2017;129(4): 456-459.

59. Filippatos TD, Liamis G, Christopoulou F, Elisaf MS. Ten common pitfalls in the evaluation of patients with hyponatremia. Eur J Intern Med. 2016;29:22-25.
60. Asano T, Aoki A, Sasaki M, et al. Hyponatremia is the valuable manifestation for initiating diagnosis of hypopituitarism in elderly. Endocr J. 2012;59(11):1015-1020.

61. Kim MI. Hypothyroidism in the elderly. In: De Groot LJ, Chrousos G, Dungan K, et al, editors. Endotext. South Dartmouth, MA; 2000.

62. Liamis G, Filippatos TD, Liontos A, Elisaf MS. Management of endocrine disease: hypothyroidism-associated hyponatremia: mechanisms, implications and treatment. Eur J Endocrinol. 2017;176(1):R15-R20.

63. Shibao C, Lipsitz LA, Biaggioni I; American Society of Hypertension Writing G. Evaluation and treatment of orthostatic hypotension. $J$ Am Soc Hypertens. 2013;7(4):317-324.

64. Hiitola P, Enlund H, Kettunen R, Sulkava R, Hartikainen S. Postural changes in blood pressure and the prevalence of orthostatic hypotension among home-dwelling elderly aged 75 years or older. J Hum Hypertens. 2009;23(1):33-39.

65. Liamis G, Filippatos TD, Elisaf MS. Correction of hypovolemia with crystalloid fluids: individualizing infusion therapy. Postgrad Med. 2015; 127(4):405-412.

66. Musch W, Verfaillie L, Decaux G. Age-related increase in plasma urea level and decrease in fractional urea excretion: clinical application in the syndrome of inappropriate secretion of antidiuretic hormone. Clin J Am Soc Nephrol. 2006;1(5):909-914.

67. Decaux G, Schlesser M, Coffernils M, et al. Uric acid, anion gap and urea concentration in the diagnostic approach to hyponatremia. Clin Nephrol. 1994;42(2):102-108.

68. Maesaka JK, Batuman V, Yudd M, Salem M, Sved AF, Venkatesan J. Hyponatremia and hypouricemia: differentiation from SIADH. Clin Nephrol. 1990;33(4):174-178.

69. Liamis G, Christidis D, Alexandridis G, Bairaktari E, Madias NE, Elisaf M. Uric acid homeostasis in the evaluation of diuretic-induced hyponatremia. $J$ Investig Med. 2007;55(1):36-44.

70. Hoorn EJ, Hotho D, Hassing RJ, Zietse R. Unexplained hyponatremia: seek and you will find. Nephron Physiol. 2011;118(3):p66-p71.

71. Musch W, Thimpont J, Vandervelde D, Verhaeverbeke I, Berghmans T, Decaux G. Combined fractional excretion of sodium and urea better predicts response to saline in hyponatremia than do usual clinical and biochemical parameters. Am J Med. 1995;99(4):348-355.

72. Ware JS, Wain LV, Channavajjhala SK, et al. Phenotypic and pharmacogenetic evaluation of patients with thiazide-induced hyponatremia. J Clin Invest. 2017;127(9):3367-3374.

73. Filippatos T, Tzavella E, Rizos C, Elisaf M, Liamis G. Acid-base and electrolyte disorders associated with the use of antidiabetic drugs. Expert Opin Drug Saf. 2017;16(10):1121-1132.

74. Filippatos TD, Tsimihodimos V, Liamis G, Elisaf MS. SGLT2 inhibitors-induced electrolyte abnormalities: an analysis of the associated mechanisms. Diabetes Metab Syndr. Epub 2017 Aug 11.

75. Rodenburg EM, Hoorn EJ, Ruiter R, et al. Thiazide-associated hyponatremia: a population-based study. Am J Kidney Dis. 2013;62(1): $67-72$.

76. Sharabi Y, Illan R, Kamari Y, et al. Diuretic induced hyponatraemia in elderly hypertensive women. J Hum Hypertens. 2002;16(9):631-635.

77. De Picker L, Van Den Eede F, Dumont G, Moorkens G, Sabbe BG. Antidepressants and the risk of hyponatremia: a class-by-class review of literature. Psychosomatics. 2014;55(6):536-547.

78. Moritz ML, Ayus JC. Maintenance intravenous fluids in acutely ill patients. N Engl J Med. 2015;373(14):1350-1360.

79. El Gkotmi N, Kosmeri C, Filippatos TD, Elisaf MS. Use of intravenous fluids/solutions: a narrative review. Curr Med Res Opin. 2017;33(3): 459-471.

80. Spasovski G, Vanholder R, Allolio B, et al. Clinical practice guideline on diagnosis and treatment of hyponatraemia. Nephrol Dial Transplant. 2014;29(Suppl 2):i1-i39.

81. Abraham WT, Decaux G, Josiassen RC, et al. Oral lixivaptan effectively increases serum sodium concentrations in outpatients with euvolemic hyponatremia. Kidney Int. 2012;82(11):1215-1222.

82. Liamis G, Filippatos TD, Elisaf MS. Treatment of hyponatremia: the role of lixivaptan. Expert Rev Clin Pharmacol. 2014;7(4):431-441. 
83. De Las Penas R, Ponce S, Henao F, et al. SIADH-related hyponatremia in hospital day care units: clinical experience and management with tolvaptan. Support Care Cancer. 2016;24(1):499-507.

84. Tzoulis P, Waung JA, Bagkeris E, et al. Real-life experience of tolvaptan use in the treatment of severe hyponatraemia due to syndrome of inappropriate antidiuretic hormone secretion. Clin Endocrinol (Oxf). 2016; 84(4):620-626.

85. Greenberg A, Verbalis JG, Amin AN, et al. Current treatment practice and outcomes. Report of the hyponatremia registry. Kidney Int. 2015; 88(1):167-177.

86. Fukui H. Do vasopressin V2 receptor antagonists benefit cirrhotics with refractory ascites? World J Gastroenterol. 2015;21(41):11584-11596.

87. Kogiso T, Tokushige K, Hashimoto E, et al. Safety and efficacy of long-term tolvaptan therapy for decompensated liver cirrhosis. Hepatol Res. 2016;46(3):E194-E200.

88. Yan L, Xie F, Lu J, et al. The treatment of vasopressin V2-receptor antagonists in cirrhosis patients with ascites: a meta-analysis of randomized controlled trials. BMC Gastroenterol. 2015;15(1):65.

89. Harbeck B, Lindner U, Haas CS. Low-dose tolvaptan for the treatment of hyponatremia in the syndrome of inappropriate ADH secretion (SIADH). Endocrine. 2016;53(3):872-873.

90. Berl T, Rastegar A. A patient with severe hyponatremia and hypokalemia: osmotic demyelination following potassium repletion. Am J Kidney Dis 2010;55(4):742-748.
91. Dellabarca C, Servilla KS, Hart B, Murata GH, Tzamaloukas AH. Osmotic myelinolysis following chronic hyponatremia corrected at an overall rate consistent with current recommendations. Int Urol Nephrol. 2005;37(1):171-173.

92. Lohr JW. Osmotic demyelination syndrome following correction of hyponatremia: association with hypokalemia. Am J Med. 1994;96(5): $408-413$.

93. Snell DM, Bartley C. Osmotic demyelination syndrome following rapid correction of hyponatraemia. Anaesthesia. 2008;63(1):92-95.

94. Tavare AN, Murray D. Central pontine myelinolysis. NEngl JMed. 2016; 374(7):e8

95. Singh TD, Fugate JE, Rabinstein AA. Central pontine and extrapontine myelinolysis: a systematic review. Eur J Neurol. 2014;21(12): 1443-1450.

96. Liamis G, Elisaf M. Treatment of hyponatremia: what the clinician needs to know. J Nephrol Res. 2015;1(1):19-21.

97. Spasovski G, Vanholder R, Allolio B, et al. Clinical practice guideline on diagnosis and treatment of hyponatraemia. Nephrol Dial Transplant. 2014;29(Suppl 2):i1-i39.

98. Filippatos TD, Liamis G, Elisaf MS. Ten pitfalls in the proper management of patients with hyponatremia. Postgrad Med. 2016;128(5):516-522.

99. Takei M, Suzuki S, Sato A, et al. Five cases of severe hyponatremia in the elderly successfully treated with low doses of hydrocortisone. Geriatr Gerontol Int. 2009;9(4):391-394.
Clinical Interventions in Aging

\section{Publish your work in this journal}

Clinical Interventions in Aging is an international, peer-reviewed journal focusing on evidence-based reports on the value or lack thereof of treatments intended to prevent or delay the onset of maladaptive correlates of aging in human beings. This journal is indexed on PubMed Central, MedLine,

\section{Dovepress}

CAS, Scopus and the Elsevier Bibliographic databases. The manuscript management system is completely online and includes a very quick and fair peer-review system, which is all easy to use. Visit http://www.dovepress. com/testimonials.php to read real quotes from published authors. 